\title{
READING PERFORMANCE, LEARNING STRATEGIES, GENDER AND SCHOOL LANGUAGE AS RELATED ISSUES - PISA 2009 FINDINGS IN FINLAND AND ESTONIA.
}

\author{
ÜLLE SÄÄLIK
}

\begin{abstract}
:
Reading is considered an important skill not only for academic success, but also for active participation in society. International student literacy assessments report gender differences in reading performance in favour of girls. These reports also show that students from schools with a minority or majority language tend to perform differently: in PISA 2009 in well-performing Finland, the Swedish-speaking schools performed at a lower level compared to the Finnish-speaking schools; in Estonia, the Estonian-speaking schools outperformed the Russian-speaking schools, despite the tests having been translated into each language.

How students learn is closely related to their results. In literacy, the more advanced thinking and learning skills known as metacognition enhance the results. Metacognitive awareness can be developed through instruction in the classroom, and this has also resulted in significant improvements for students with rather low learning abilities. As it is teachers' and schools' opportunity to help their students by teaching these skills, their awareness of useful strategies could presumably be dependent on the school.

So far only the PISA 2009 study has included student awareness of different learning strategies; therefore, the data here enable us to analyse how learning strategies relate to reading, gender or school language. In the current paper, the issues of reading proficiency, learning strategies, gender and school language are considered jointly. Alongside the theoretical background, results from several analyses of PISA 2009 are discussed to show how student awareness and choice of different learning strategies could explain the variation in reading results in boys and girls at student and school levels, and predict their reading test results. The two-level modelling analysis was used as a research method, since it allows us to draw reasonable statistical inferences for regression-type analyses under a hierarchical data structure, and where the factor of individuals being influenced by the group they belong to is explicitly taken into account.
\end{abstract}

Acknowledgements:

This research was supported by European Social Fund's Doctoral Studies and Internationalization Programme DoRa, which is carried out by Foundation Archimedes, project 1.2.0401.09-0070.

\section{Keywords:}

reading, learning strategies, gender, school language, multilevel modelling

JEL Classification: 129, C55

\author{
Authors: \\ ÜLLE SÄÄLIK, University of Tartu, Estonia, Email: ulle.saalik@ut.ee
}




\section{Citation:}

ÜLLE SÄÄLIK (2015). Reading performance, learning strategies, gender and school language as related issues - PISA 2009 findings in Finland and Estonia.. International Journal of Teaching and Education, Vol. III(2), pp. 17-30., 10.20472/TE.2015.3.2.002 


\section{Introduction}

Reading literacy is considered to be an essential life skill, and has been researched and analysed in several ways, but problems with low-achievers remain unresolved. There is still a worryingly high number of individuals struggling with reading in so many countries, as reported by several international and national studies. The reasons for these problems with reading literacy are constantly in focus, and some issues seem to appear more often such as under achieving males or the strong negative effect of low socioeconomic status (Garbe et al, 2010; OECD, 2010b). Therefore, these aspects are also considered in this paper.

In some countries, students from schools with a different instructional language tend to perform at a lower level, causing concern for educators and governments. In the PISA $^{1} 2009$ study in Finland, students in Swedish-speaking schools obtained lower reading literacy scores (Brink, Nissinen \& Vettenranta, 2013; Harju-Luukkainen \& Nissinen, 2011), and in Estonia, students in Russian-speaking schools performed at a statistically significant lower level in reading compared to their peers in Estonianspeaking schools (Mikk et al., 2012). Regardless of the instructional language of the school, according to education policy in Finland and Estonia, all schools are expected to ensure educational equality (Brink, Nissinen and Vettenranta, 2013; Eesti Haridusministeerium, 2004; Ministry of Education and Culture, 2012), and therefore, it could be acknowledged as a problem if some schools still perform at a lower level, causing concern for parents when choosing the best school for their children (Malin, 2007).

The current paper aims to provide a short overview of the findings of the PISA ${ }^{1} 2009$ reading test results, based on multilevel modelling analyses, revealing how the variation in reading literacy test scores at student and school levels is attributable to student awareness and use of different learning strategies, and how a raise in student awareness and use of learning strategies would predict their reading test results.

\section{Reading comprehension}

As the PISA ${ }^{1} 2009$ study is so far the only large-scale reading study with a representative sample that includes data about student awareness and use of learning strategies, data form this study were used to analyse the relations and effect of reading and learning strategies. Therefore, the notion of reading comprehension and reading literacy is here based on the PISA definition: "students' ability to understand, use and reflect on written texts; students were expected to demonstrate their proficiency in accessing and retrieving information, forming a general understanding of the text, interpreting it and reflecting on its contents and features" (OECD, 2010a, p.14).

Consequently, a young person's primitive reading acquisition is not what is being considered here, but the more advanced ability to cope with printed or written information (Perfetti and Marron, 1998). The International Reading Association (2012, p.2) defined adolescent literacy as the ability to read, write, understand and interpret, and discuss multiple texts across multiple contexts. As the PISA study monitors 15-

\footnotetext{
1 PISA - the Programme for International Student Assessment is a large-scale on-going programme for monitoring 15-year-olds performance in reading, maths and science, conducted by the OECD.
} 
year-olds, the age of entering the next level of education, in which the ability to work with long written texts is rather essential, higher level reading skills are expected to be obtained by that age.

The traditional view of reading comprehension sees a passive reader acquiring a set of sub-skills and routinely applying them to all texts, while the new cognitive view assumes a reader to be active, constructing meaning through the integration of existing knowledge and the flexible use of strategies (Dole et al., 2004). A previously conducted analysis of PISA 2009 Estonian data showed that low-performing students tend to report less use of advanced metacognitive reading strategies and more often preferring traditional methods such as memorizing or control strategies (Mikk et al., 2012). The question of how student awareness of learning strategies could be related to reading performance therefore arose.

\section{Learning Strategies}

Learning skills are defined as more or less automatic routines, while strategies emphasize reasoning, implying metacognitive awareness leading to regulation and repair in the learning process if needed (Dole et al., 2004). Learning strategy is understood as the intentional cognitive processing performed by a learner at the time of learning intended to improve the learning (Mayer, 2008). Learning strategies are a set of one or more procedures that a person acquires to facilitate performance on a learning task, varying depending on the nature of the task (Riding and Rayner, 2000, p.80).

Studies have shown that students are more successful with certain reading tasks, when they are taught to recognise and use higher order thinking skills known as metacognitive learning strategies. Metacognitive learning strategies have been proven to have a highly positive effect on improving learning results; furthermore, some considerable improvement in reading results has also been noted for students with low academic ability (Jones, 2007; Pennequin et al., 2010; van der Stel and Veenman, 2008, 2010).

Students can be instructed to monitor their own understanding - they can be trained to recognize and use different thinking and learning skills and to identify the situations in which these skills and methods are useful (Mayer, 2008, Simister, 2007; van der Stel and Veenman, 2010). This instruction is something the teacher does to promote learning in the student, including the intended instruction manipulations (i.e. described in the national curriculum) and those actually implemented in classrooms, and learning is a cognitive change from not knowing to knowing, or changes in the learners' knowledge due to experience, with the following three aspects: behavioural, cognitive and contextual (Mayer, 2008, p.8).

The development of such thinking skills goes through talk and dialogic teaching in the classroom, while freely articulating ideas and viewpoints in a risk-free environment, and that places the teachers' work at the heart of this task (Jones, 2007). A largescale comparative study of good practices in teaching reading ${ }^{2}$ found that when teachers practiced teaching both cognitive and meta-cognitive strategies continuously, encouraging reasoning for learning, thinking aloud, allowing and even encouraging struggling readers to work in pairs or groups with more skilled peers, this was

${ }^{2}$ ADORE-Teaching Adolescent Struggling Readers 
successful and helped everyone to become more fluent readers (Steklàcs, 2010).

\section{Gender}

In educational studies some confusion over the two terms "sex" and "gender" occurs. A person's sex is a rather biological and physiological matter - female or male, while a person's gender is a social and historical construct, referring to economic and cultural attributes and opportunities associated with being male or female (DesprezBouanchaud et al., 1987, p.20-21).

In the current paper the term "gender" is used due to its social attribute in the school context, which, whether we like it or not, are becoming more and more womencentred, and therefore, certain gender-specific expectations or stereotypes might influence the student's performance and attitudes while learning (EACEA, 2010; Shekkam, Xiao-yain and Wai-yip, 2013; Väljaots, 2013).

The current situation with regard to gender studies in education could be described as an on-going matter with governments and educators still looking for justice, but often lacking clear standpoints on what is understood as justice or how it should be achieved (Holz and Shelton, 2013). It is known that boys and girls perform differently at school, and reading is one of the distinguishing subjects. But is it just the innate nature of gender affecting boys' and girls' learning outcomes, or is it something that could be and needs to be improved through certain instructional practices at schools? It could be assumed that the way we approach learning is acquired from the surrounding environment, imitating others or doing what we are taught to do.

\section{School as a group effect and contextual factor}

Influences from the surrounding environment and other people's attitudes are collectively referred to as the group effect on individual outcomes, considering the dependence of individuals on the groups they belong to (Hox, 2010). It has been stated that schools with more high-achieving students are more likely to have highachieving cultures (Ma and Willms, 2004). In such a school context with more highachieving students and more appropriate instructional practices, students tend to have more positive reading attitudes and improved reading skills, resulting in better reading attainment (Shek-kam, Xiao-yain and Wai-yip, 2013, p.264).

It is not very clear whether the effect of learning strategies on reading literacy test results depends more on the individual characteristics of students, determined by the innate nature of gender as critically asserted by Ivinson and Murphy (2007), or whether a group effect is traceable, revealing possible sources of systematic variation caused by the fact that students in schools are exposed to the same kind of treatment by the same teachers or similar teaching practices; thereby, being somewhat homogenized to perform in a more similar way (Malin, 2005). And, as the schools with a similar instructional language have been found to perform at a similarly lower or higher level, this could be affected by the educational practices shared in those schools. Therefore, the contextual factor defined by the school's instructional language was included in the analyses to control for such contextual effects. 


\section{Data and methods}

The following PISA 2009 data $^{3}$ were used for the analysis: the plausible value of 1 as a reading comprehension test score, variables from student questionnaires (student awareness and use of different learning strategies, student perceptions of the disciplinary climate and teacher-student relations), and the background variables of student gender and school instructional language. A more detailed description of these variables is given in Appendix 1.

The sample from Finland consisted of 147 Finnish-speaking schools with 2,215 girls and 2,188 boys, and 56 Swedish-speaking schools with 739 girls and 668 boys. The sample from Estonia included 138 Estonian-speaking schools with 1,812 girls and 1,922 boys, and 37 Russian-speaking schools or schools with mixed languages with 485 girls and 508 boys.

In the school studies, single student observations are not completely independent, as the data are hierarchically structured using two levels students nested within the schools. Students in the same school tend to perform more similarly, indicating the group effect (Hox, 2010). As the group effect was identified in the countries analysed here, a multilevel approach was necessary, and statistical analyses were conducted using multilevel modelling in which these dependencies are taken into account (e.g. Goldstein, 2011; Hox, 2010).

Multilevel modelling makes it possible to draw correct statistical inference for regression-type analyses under a hierarchical data structure. The regression coefficient estimates show the expected change in student reading test scores if the index value - the explanatory variable (i.e. student awareness and use of a certain learning strategy) - was increased by 1 unit.

Separate intercepts for each gender and language subgroup were fitted to apply a fairer statistical approach towards these subgroups, and to control for the effect of gender and school language. Therefore, separate dichotomous explanatory variables for each student group were included. To purify the results from the effect of a relatively strong background factor, the economic-social-cultural status (ESCS) variable was added to the null model, and to form a baseline model. The variance components of the full model were compared to the variance components of the baseline model. The proportional reduction in variance components (Snijders and Bosker 2002, 99) was used as a measure for the explained proportion of variance, the total variance divided into two variance components (between schools and between students within schools).

The statistical analyses were conducted using the MLwiN 2.29 software (Rasbash et al., 2013). Student weights were used in modelling. Separate analyses were conducted with the data sets from Finland and Estonia.

\section{Learning strategies explaining the variation in reading}

In most PISA countries, a great proportion of the variation in student performance has been attributable to differences between schools (Malin, 2005; OECD, 2010c, p. 2627). The same tendency was discovered in Nordic and Baltic countries. In Nordic

\footnotetext{
${ }^{3}$ More precise description of the methodology behind PISA data is available in OECD materials (OECD 2009, 81; OECD 2009, 99-102; OECD, 2010a, 15-16; OECD, 2012).
} 
countries about $9-16 \%$ and in the Baltics about $21-32 \%$ of the total variation in reading test results was due to differences between schools (Säälik, Malin and Nissinen, unpublished manuscript), in other words, the difference between students' reading results appear to be partly dependent on the school they go to.

In one of the previous analyses of Estonian data, the metacognitive learning strategies alone (in a single-factor model) were found to explain about $30 \%$ of the betweenschool variation and 13-15\% of the between-student variation (Säälik, Malin and Nissinen, 2013), but as other potentially influential factors were not taken into account in this analysis, the question remained whether the effect is still present when these factors are considered.

In the current analysis, when the background factors (gender, school language and ESCS) were added to the model, and therefore, controlled for, student awareness and use of learning strategies still played an important role in explaining both student and school level variation in reading performance. If all learning strategies and the economic-social-cultural status are added to the model, this would explain about $55 \%$ of between-school variation both in Finland and Estonia.

In Finland, the variables for learning strategies reduced about 22-27\% of the variation, while in Estonia this was about 16-20\%. In Finland, the girls' reading results seemed to be more influenced by the learning strategies than the boys' in both Finnish and Swedish speaking schools; in the case of the girls, the reduction in the variance component was larger than that for the boys. In Estonia, quite the opposite, the learning strategies explained more of the boys' variance than that of the girls' with about a $16-18 \%$ reduction of the variance for girls and $20 \%$ for boys (Säälik, in press).

\section{Effects on Reading Literacy Performance}

The regression coefficients in Table 1 show us that both the metacognitive strategies would help raise student reading test results. If the student's index of awareness of the summarizing strategy was 1 point higher, he or she would achieve about 21-24 more points. With an awareness of the understanding and remembering strategy, their score would be raised by 14-15 points. At the same time, the traditional memorization strategy does not seem to help. If the student tried to apply memorization, the reading score would drop by 10-15 points. The control strategies show a higher effect in Finland with 13 points, and slightly less in Estonia with about 9 points. The elaboration strategy appears less relevant. 
Table 1 Regression coefficient estimates from the full multilevel model, standard errors in brackets

\begin{tabular}{|c|c|c|}
\hline & Finland & Estonia \\
\hline Variable & Coefficient (s.e.) & Coefficients (s.e.) \\
\hline Metacognitive: summarizing & $24.1^{*}(1.21)$ & $21.4^{*}(1.22)$ \\
\hline $\begin{array}{l}\text { Metacognitive: Understanding and } \\
\text { remembering }\end{array}$ & $14.4^{*}(1.13)$ & $14.9 *(1.21)$ \\
\hline Memorization & $-10.2^{*}(1.36)$ & $-15.1^{*}(1.56)$ \\
\hline Elaboration & $1.9(1.25)$ & $5.2^{*}(1.4)$ \\
\hline Control strategy & $13.0^{*}(1.4)$ & $8.9 *(1.5)$ \\
\hline
\end{tabular}

* Statistically significant $p<.05$. School language, gender and economic-social-cultural status controlled for. The complete explanation of variables is given in Appendix 1.

\section{Conclusions and discussion}

During the last few decades, metacognitive ability has been the focus of educational studies; and its crucial role in improving learning outcomes has been proved in the present study. Reading comprehension and student awareness and use of learning strategies appear to be closely related to student gender and school language. Learning strategies explained a large part of this effect, when the effects of gender and school language were controlled for. One third of the variation at school level and about one fifth of the variation at student level could be attributable to the awareness and use of five learning strategies among students. When combined with economicsocial-cultural status, learning strategies would explain half of the between-school differences and more or less a quarter of the individual differences.

When discussing the possible influence of the surroundings on a student's learning outcomes, both the intended manipulations (i.e. national curriculum with its requirements or suggestions on instructional practices) and actually implemented instructional practices should be considered. Although the national curriculum usually establishes certain educational practices that are expected to be implemented in all schools, it might be that the actual implementations vary from school to school. That could be assumed as one of the reasons why students in schools with a different instructional language tend to report different awareness and use of learning strategies.

The discovered evidence (between-school variability explained by learning strategies, particularly metacognitive strategies) leads to the assumption that in some schools these skills are developed and in others not so much. Unfortunately, the PISA data do not allow us to draw such a clear conclusion; therefore, this is a question for further research.

Teachers are able to contribute to their students' success in many ways; for example, 
developing learning skills is still in the teachers' hands while helping students through a dialogic approach to teaching using open questions, helping them develop skills through self-reflective talk and instructing others among other practices (Jones, 2007; Pennequin et al., 2010; van der Stel and Veenman, 2010; Simister, 2007; Steklàcs, 2010). When reading strategies are taught to students, and these were associated with student reading attitude scores, it explained about $4 \%$ of the school-level variance in the Hong-Kong PIRLS studies, suggesting that students may use those reading strategies to read successfully, and reading motivation and interest may be enhanced by successful reading experiences (Shek-kam, Xiao-yain and Wai-yip, 2013, p.259260).

It could be stated that in the case of real-life reading tasks, similar to the PISA reading literacy test tasks, metacognitive learning skills help much more than traditional ways of learning such as learning by heart (memorizing), elaboration or control strategies. Less successful teachers are said to rely more on traditional closed forms of questioning, but these 'right answer' methods do not help students develop high-level reading skills (Mercer and Howe, 2012).

It is possible to teach self-regulated learning when teachers regularly clarify the use of useful reading strategies, repeatedly model and demonstrate strategies in the context of school-related or moreover real-world-related reading (Steklàcs, 2010). To facilitate students' independent reading, it has been found to be important to teach learning skills and strategies explicitly, thus improving individual students' reading ability as well as enlarging positive peer-influence in schools (Shek-kam, Xiao-yain and Wai-yip, 2013).

It has been pointed out that our schools tend to turn into women-centred systems, where boys are constantly compared with girls, resulting in low self-esteem among boys (Väljaots, 2013). So far there are no explicit scientific views on whether gender should or should not be compared at all, whether it is possible or necessary to equalize them, or which gender-independent measures could be exploited to that end. Yet, some authors state the need for a policy decision to achieve changes in these differences with different approaches in learning, focusing on high-achieving girls in mathematics and on low-achieving boys in reading to yield the strongest educational benefits (EACEA, 2010; Holz and Shelton, 2013; Stoet and Geary, 2013).

It is important to recognize the complexity in the gender mediation of learning, as pointed out by Ivinson and Murphy (2007), revealing how unclear individual components of achievement are and how difficult they are to identify when individuals are constantly exposed to and affected by social and cultural influences. Logan and Johnston (2010) also highlight the multi-faceted nature of gender differences, and therefore, they suggest that all children, regardless of gender, would benefit from an increased understanding of the most effective ways of approaching reading and the cognitive skills supporting its development.

Nevertheless, the mystery behind the mechanisms in people's brains while learning is worth researching. Simply recognizing right or wrong strategies for certain reading tasks appears to distinguish the successful readers from the poor readers. And that, in turn, appears not to be purely a student's individual characteristic, but has links to the school the student attends. Obviously, discovering the most influential factors behind these problems would fascinate researchers, but so far cross-sectional studies only allow us to examine relationships, make assumptions resulting from regression analyses, or make assumptions about the variation in results. At the same time, 
longitudinal studies and experiments, covering a rather small or specific range of participants, do not fully provide sufficient scope for generalising about entire populations.

\section{References}

BRINK, S., NISSINEN, K. and VETTENRANTA, J. (2013) Equity and excellence. Evidence for policy formulation to reduce the difference in PISA performance between Swedish speaking and Finnish speaking students in Finland. Jyväskylä: Finnish Institute for Educational research. Available from: https://ktl.jyu.fi/en/publications/g047.pdf [Accessed: $18^{\text {th }}$ January 2015].

DESPREZ-BOUANCHAUD, A., DOOLAEGE, J. and RUPRECHT, L. (1987) Guidelines on genderneutral language. Paris: UNESCO. Available from: http://unesdoc.unesco.org/images/0011/001149/114950Mo.pdf [Accessed: $15^{\text {th }}$ March 2015].

DOLE, J., DUFFY, G. G., ROEHLER, L. R. and PEARSON, D. P. (2004) Moving from the Old to the New. Research on reading comprehension instruction. In Wray, D. (ed.). Literacy. Major Themes in Education, II, Reading: Processes and Teaching. NY: RoutledgeFalmer.

EACEA (2010) Gender Differences in Educational Outcomes. Study on the Measures Taken and the Current Situation in Europe. Brussels: Eurydice. doi: 10.2797/3598

MINISTRY OF EDUCATION AND CULTURE (2012) Education and Research 2011-2016. A development plan. Reports of the Ministry of Education and Culture, Finland 2012:3. Available from: http://www.minedu.fi/export/sites/default/OPM/Julkaisut/2012/liitteet/okm03.pdf?lang=en [Accessed: $17^{\text {th }}$ January 2015].

EESTI HARIDUSMINISTEERIUM (2004) Eesti tegevuskava "Haridus kõigile" [Estonian development plan "Education for All"]. Available from: http://www.unesco.ee/public/documents/Haridus koigile arengukava 2004.pdf $\left[\right.$ Accessed: $10^{\text {th }}$ January 2015].

GARBE, C. et al. (2010) Characteristics of adolescent struggling readers. In Garbe, C., Holle, K. \& Weinhold, S. (eds.) ADORE- Teaching struggling adolescent readers in European countries. Key elements of good practice. Frankfurt am Main: Peter Lang.

GOLDSTEIN, H. (2011) Multilevel statistical models. $4^{\text {th }}$ edition. Chichester: Wiley.

HARJU-LUUKKAINEN, H. and NISSINEN, K. (2011) Finlandssvenska 15-åriga elevers resultatnivå I PISA 2009 -undersökningen. Jyväskylä: Finnish Institute for Educational research.

HOLZ, O. and SHELTON, F. (eds.) (2013). Education \& Gender. Gender-Specific Education in Different Countries. Historical aspects - current trends. Münster, New York, München, Berlin: Waxmann.

HOX, J. J. (2010) Multilevel Analysis- Techniques and Applications. NY: Routledge.

IVINSON, G. and MURPHY, P. (2007) Rethinking Single-Sex Teaching. Gender, school subjects and learning. NY: Open University Press, McGraw Hill Education.

INTERNATIONAL READING ASSOCIATION. (2012) Adolescent literacy (Position statement, Rev. 2012 ed.). Newark, DE. Available from: http://www.reading.org/Libraries/resources/ps1079 adolescentliteracy rev2012.pdf [Accessed: $18^{\text {th }}$ January 2015].

JONES, D. (2007) Speaking, listening, planning and assessing: the teacher's role in developing metacognitive awareness. Early Child Development and Care, Vol. 177, Nos 6 and 7, p.569-579. doi: $10.1080 / 03004430701378977$

LOGAN, S. and JOHNSTON, R. (2010) Investigating gender differences in reading. Educational Review, Vol.62, No.2, May 2010, p.175-187.

MA, X. and WILLMS, J. D. (2004) School disciplinary climate: Characteristics and effects on eighth grade achievement. Canadian Journal of Education, 25, p.41-44.

MALIN, A. (2005) School differences and inequities in educational outcomes. PISA 2000 results of 
reading literacy in Finland. (Doctoral dissertation). University of Jyväskylä.

MALIN, A. (2007) Is learning to read dependent on the school in Finland? In Linnakylä, P. \& Arffman, I. (eds.) Finnish Reading Literacy. When quality and equity meet. Jyväskylä: Jyväskylä University Press.

MAYER, R. E. (2008) Learning and Instruction. Upper Saddle River (N.J.), Columbus (Ohio) 2Q21WA: Pearson/Merrill/Prentice Hall.

MERCER, N. and HOWE, C. (2012) Explaining the dialogic processes of teaching and learning: The value and potential of sociocultural theory. Learning, Culture and Social Interaction 1, p.12-21.

MIKK, J. et al. (2012) Eesti PISA 2009 kontekstis: tugevused ja probleemid. Programmi Eduko uuringutoetuse kasutamise lepingu aruanne [Estonia in PISA 2009 context: strengths and issues. The Eduko programme grant report]. Available from:: http://www.hm.ee/index.php?048181 [Accessed: $30^{\text {th }}$ January 2013].

OECD (2009) PISA Data Analysis Manual: SAS, Second Edition. OECD Publishing.

OECD (2010a) PISA 2009 Assessment Framework: Key Competencies in Reading, Mathematics and Science. Available from: http://www.oecd.org/dataoecd/11/40/44455820.pdf $\left[\right.$ Accessed: $6^{\text {th }}$ June 2012].

OECD (2010b. PISA 2009 results: Learning to learn- student engagement, strategies and practices (Vol III). Available from: http://dx.doi.org/10.178/9789264083943-en [Accessed: $5^{\text {th }}$ August 2012].

OECD (2010c). PISA 2009 Results: What Makes a School Successful? - Resources, Policies and Practices (Vol IV). Available from: http://dx.doi.org/10.1787/9789264091559-en [Accessed: $10^{\text {th }}$ January 2013].

PENNEQUIN, V., SOREL, O., NANTY, I. and FONTAINE, R. (2010) Metacognition and low achievement in mathematics: The effect of training in the use of metacognitive skills to solve mathematical word problems. Thinking and Reasoning, 16 (3), p.198-220.

PERFETTI, C. A. and Marron, M. A. (1998) Learning to read: Literacy acquisition by children and adults. In Wagner, D. A. (ed.). Advances in adult literacy research and development. Hampton Press.

Available

from: http://www.pitt.edu/ perfetti/PDF/Learning\%20to\%20read,\%20literacy\%20acq\%20by\%20children \%20and\%20adults-\%20Marron.pdf [Accessed: $18^{\text {th }}$ January 2015].

RASBASH, J. et al. (2012) A User's Guide to MLwiN. Version 2.26. Centre for Multilevel Modelling, University of Bristol.

SHEK-KAM, T., XIAO-YAIN, X. and WAI-YIP, L. (2013) The influences of gender, reading ability, independent reading, and context on reading attitude. A multilevel analysis of Hong Kong data from PIRLS. Written Language \& Literacy 16:2, p.241-271. doi: io.iO75/wll.i6.2.O5tse

SIMISTER, C. J. (2007) How to Teach Thinking and Learning Skills. London: Paul Chapman Publishing, A SAGE Publication Company.

SNIJDERS, T. and BOSKER, R. (2002) Multilevel Analysis. An Introduction to Basic and Advanced Multilevel Modeling. London: Sage Publications.

STEKLÀCS, J. (2010) Key Element No.6: Teaching Cognitive and Meta-Cognitive Reading Strategies. In Garbe, C., Holle, K. \& Weinhold, S. (eds.) ADORE- Teaching struggling adolescent readers in European countries. Key elements of good practice. Frankfurt am Main: Peter Lang.

STOET, G. and GEARY, D. C. (2013) Sex Differences in Mathematics and Reading Achievement Are Inversely Related: Within- and Across-Nation Assessment of 10 Years of PISA Data. PLoS ONE 8(3): e57988. doi: 10.1371/journal.pone.0057988

SÄÄLIK, Ü. (in press). Learning strategies explaining boys' and girls' reading performance in schools with different language. Procedia - Social and Behavioral Sciences. Elsevier.

SÄÄLIK, Ü., MALIN, A. and NISSINEN, K. (2013) The Role of Learning Strategies in PISA 2009 in Estonia: Metacognitive Skillfulness Giving Readers a Head Start. In Mikk, J., Veisson, M. \& Luik, P. (eds.) Change in Teaching and Learning. Frankfurt am Main: Peter Lang. 
VAN DER STEL, M. and VEENMAN, M. V. J. (2008) Relation between intellectual ability and metacognitive skillfulness as predictors of learning performance of young students performing tasks in different domains. Learning and Individual Differences 18. Elsevier. doi: 10.1016/j.lindif.2007.08.003

VAN DER STEL, M. and VEENMAN, M. V. J. (2010) Development of metacognitive skillfulness: A Longitudinal study. Learning and Individual Differences 20. Elsevier. doi: 10.1016/j.lindif.2009.11.005

VÄLJAOTS, M. (2013) Gender Research in Estonia against the Background of Traditional Education. In Holz, O. \& Shelton, F. (eds.). Education \& Gender. Gender-Specific Education in Different Countries. Historical aspects - current trends. Münster, New York, Münhen, Berlin: Waxmann. 
Appendix 1. Description of student background questionnaire indices for the PISA study used in the paper.

\begin{tabular}{|c|c|c|}
\hline $\begin{array}{l}\text { Name of the } \\
\text { index }\end{array}$ & Acronym & Sample questions \\
\hline $\begin{array}{l}\text { Metacognition: } \\
\text { Understanding } \\
\text { and } \\
\text { remembering }\end{array}$ & UNDREM & $\begin{array}{l}\text { Reading task: You have to understand and remember } \\
\text { the information in a text. } \\
\text { How do you rate the usefulness of the following } \\
\text { strategies for understanding and memorizing the text? } \\
\text { (Answers on a six-point scale) } \\
\text { A) I concentrate on the parts of the text that are easy } \\
\text { to understand; B) I quickly read through the text twice; } \\
\text { C) After reading the text, I discuss its content with } \\
\text { other people; D) I underline important parts of the text; } \\
\text { E) I summarize the text in my own words; and F) I } \\
\text { read the text aloud to another person. }\end{array}$ \\
\hline $\begin{array}{l}\text { Metacognition: } \\
\text { Summarizing }\end{array}$ & METASUM & $\begin{array}{l}\text { You have just read a long and rather difficult two-page } \\
\text { text about fluctuations in the water level of a lake in } \\
\text { Africa. You have to write a summary. How do you rate } \\
\text { the usefulness of the following strategies for writing a } \\
\text { summary of this two-page text? (Answers on a six- } \\
\text { point scale) } \\
\text { A) I write a summary. Then I check that each } \\
\text { paragraph is covered in the summary, because the } \\
\text { content of each paragraph should be included; B) I try } \\
\text { to copy out accurately as many sentences as } \\
\text { possible; C) Before writing the summary, I read the } \\
\text { text as many times as possible; D) I carefully check } \\
\text { whether the most important facts in the text are } \\
\text { represented in the summary; and E) I read through the } \\
\text { text, underlining the most important sentences, then I } \\
\text { write them in my own words as a summary. }\end{array}$ \\
\hline $\begin{array}{l}\text { Control } \\
\text { strategies }\end{array}$ & CSTRAT & $\begin{array}{l}\text { When you are studying, how often do you do the } \\
\text { following? (Answers on a four-point scale) } \\
\text { When I study, I start by figuring out what exactly I } \\
\text { need to learn } \\
\text { When I study, I check if I understand what I have read } \\
\text { When I study, I make sure that I remember the most } \\
\text { important points in the text } \\
\text { When I study, I try to figure out which concepts I still } \\
\text { haven't really understood } \\
\text { When I study and I don't understand something, I look } \\
\text { for additional information to clarify this }\end{array}$ \\
\hline
\end{tabular}




\begin{tabular}{|l|l|l|}
\hline $\begin{array}{l}\text { Memorization } \\
\text { strategies }\end{array}$ & MEMOR & $\begin{array}{l}\text { When you are studying, how often do you do the } \\
\text { following? (Answers on a four-point scale) } \\
\text { When I study, I try to memorize everything that is } \\
\text { covered in the text } \\
\text { When I study, I read the text so many times that I can } \\
\text { recite it } \\
\text { When I study, I try to memorize as many details as } \\
\text { possible } \\
\text { When I study, I read the text over and over again }\end{array}$ \\
\hline $\begin{array}{l}\text { Elaboration } \\
\text { strategies }\end{array}$ & ELAB & $\begin{array}{l}\text { When you are studying, how often do you do the } \\
\text { following? (Answers on a four-point scale) } \\
\text { When I study, I try to relate new information to prior } \\
\text { knowledge acquired in other subjects } \\
\text { When I study, I figure out how the text information fits } \\
\text { in with what happens in real life } \\
\text { When I study, I try to understand the material better by } \\
\text { relating it to my own experiences. } \\
\text { When I study, I figure out how the information might } \\
\text { be useful outside school }\end{array}$ \\
\hline Economic, \\
cultural status
\end{tabular}

